\title{
Management of undernutrition and failure to thrive in children with congenital heart disease in low- and middle-income countries
}

\author{
Andrew C. Argent, ${ }^{1,2}$ Rakhi Balachandran, ${ }^{3}$ Balu Vaidyanathan, ${ }^{4}$ Amina Khan, ${ }^{5}$ R. Krishna Kumar ${ }^{4}$ \\ ${ }^{1}$ School of Child and Adolescent Health, University of Cape Town; ${ }^{2}$ Paediatric Intensive Care, Red Cross War Memorial \\ Children's Hospital, Rondebosch, Cape Town, South Africa; ${ }^{3}$ Department of Cardiac Anesthesiology, Pediatric Cardiac \\ Intensive Care; ${ }^{4}$ Amrita Institute of Medical Sciences and Research Centre, Amrita Vishwa Vidyapeetham, Cochin, \\ Kerala, India; ${ }^{5}$ Heart Lungs $\mathcal{E}$ Vascular Service Line, Aga Khan University Hospital, Karachi, Pakistan
}

\begin{abstract}
Poor growth with underweight for age, decreased length/height for age, and underweight-for-height are all relatively common in children with CHD. The underlying causes of this failure to thrive may be multifactorial, including innate growth potential, severity of cardiac disease, increased energy requirements, decreased nutritional intake, malabsorption, and poor utilisation of absorbed nutrition. These factors are particularly common and severe in low- and middle-income countries.

Although nutrition should be carefully assessed in all patients, failure of growth is not a contraindication to surgical repair, and patients should receive surgical repair where indicated as soon as possible.

Close attention should be paid to nutritional support - primarily enteral feeding, with particular use of breast milk in infancy - in the perioperative period and in the paediatric ICU. This nutritional support requires specific attention and allocation of resources, including appropriately skilled personnel.

Thereafter, it is essential to monitor growth and development and to identify causes for failure to catch-up or grow appropriately.
\end{abstract}

Keywords: CHD; low- and middle-income countries; nutrition; cardiac surgery; paediatric intensive care

Received: 15 September 2017; Accepted: 15 September 2017

$\mathrm{M}$ ANY CHILDREN WITH CHD ARE UNDERWEIGHT for age ${ }^{1-11}$ and/or stunted - even at an early age. Being significantly underweight for age and wasted has been associated with higher perioperative morbidity and mortality in children with $\mathrm{CHD} .{ }^{12}$ In addition, the perioperative period is frequently complicated by difficulties with enteral nutrition ${ }^{10,13}$ and potentially with increased nutritional loss associated with problems such as chylothorax.

There is a significant burden of childhood undernutrition in low- and middle-income countries where some $90 \%$ of the children born with CHD across the world live. ${ }^{14}$ The co-existence of CHD increases

Correspondence to: A. C. Argent, Professor, School of Child and Adolescent Health, University of Cape Town and, Medical Director, Pediatric Intensive Care, Red Cross War Memorial Children's Hospital, Klipfontein Road, Rondebosch, Cape Town 7700, South Africa. Tel: +27 21658 5369; Fax: +27 21689 1287; E-mail: Andrew.Argent@uct.ac.za the likelihood and severity of undernutrition, and this adds to challenges for the management of $\mathrm{CHD}$ including resource constraints; late presentation and diagnosis; and perioperative infection. ${ }^{15-18}$ The number of children, including infants and newborns being operated for $\mathrm{CHD}$, has recently increased in these regions. ${ }^{15}$

This review seeks to summarise existing evidence on prevalence of undernutrition and CHD and its impact on surgical outcomes with a focus on implications for low- and middle-income countries. An effort has been made to identify specific gaps in knowledge as a basis for future multicentre studies.

\section{Definition of malnutrition in CHD}

In the context of $\mathrm{CHD}$, it is important to reach a clear consensus on what is meant by malnutrition. Simple 


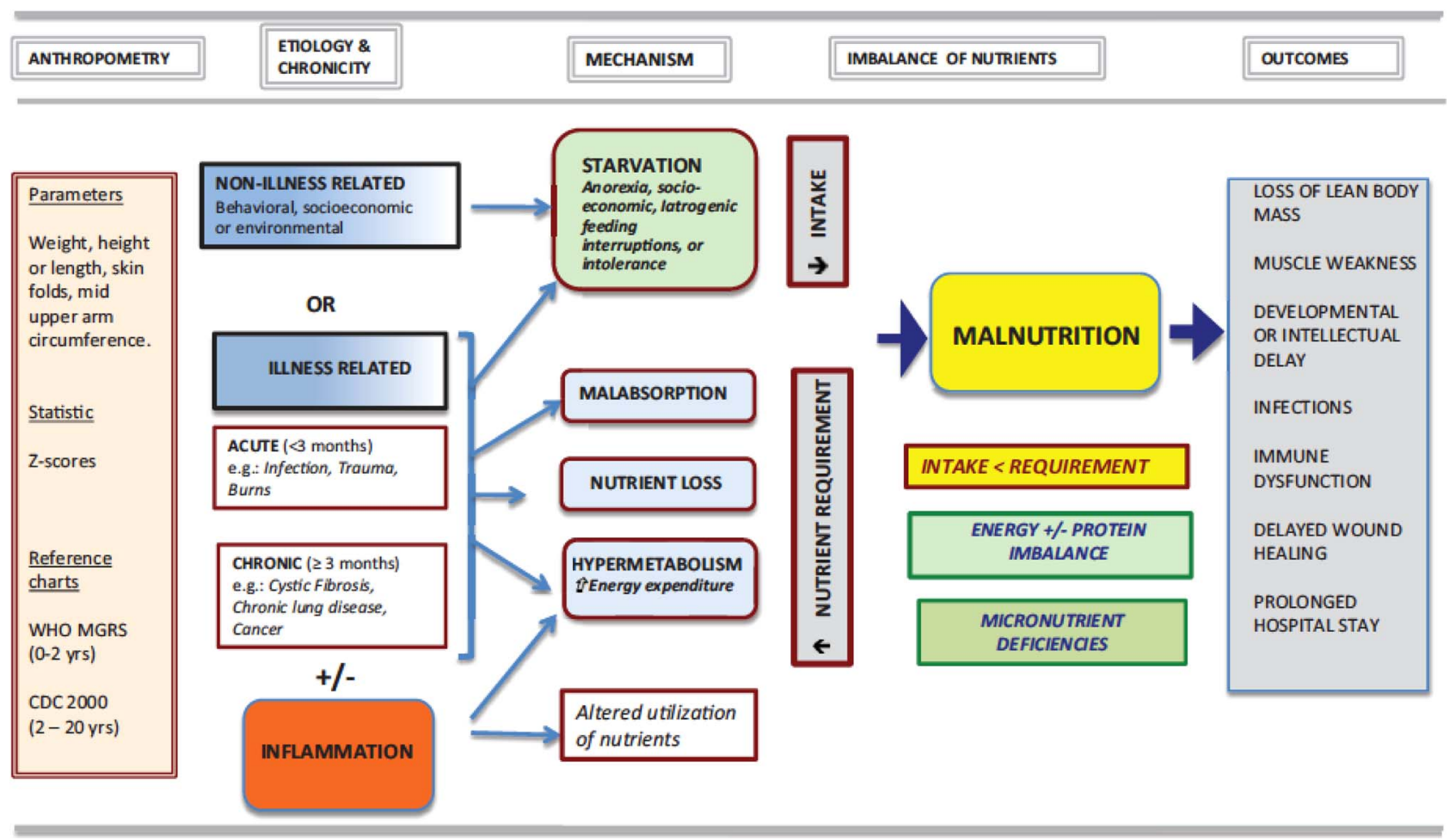

Figure 1.

An approach to nutrition in the child with failure to grow or to gain weight, from Mehta et al. ${ }^{22}$

measurements, such as height, weight, skinfold thickness, or mid-upper arm circumference, and their relationships, for example, weight-for-height, have been the basis of most definitions of nutritional status. ${ }^{19}$ It is not possible to exclude malnutrition on the grounds of normal anthropometry alone, as there may be children with acute malnutrition who fall within the "normal" ranges for standard anthropometry. ${ }^{20}$ Green Corkins has recently highlighted the importance of a full clinical evaluation - versus simply viewing anthropometry - in the assessment of nutrition status in children. ${ }^{21}$

Mehta et al defined malnutrition as "an imbalance between nutrient requirement and intake, resulting in cumulative deficits of energy, protein, or micronutrients that may negatively affect growth, development, and other relevant outcomes" ${ }^{22}$ (see Fig 1). Ideally, any assessment of nutrition and investigations on the role of nutrition in patient management should include data regarding growth over a period of time: actual dietary intake available (and provided); evidence for malabsorption; evidence of inflammatory processes; and evidence of any underlying disease. ${ }^{23}$

\section{Failure to thrive in children with CHD}

The basis of growth failure or underweight in CHD appears to be multifactorial and may differ in aetiology from patient to patient. It includes the underlying cardiac anomaly, ${ }^{24}$ haemodynamic factors, hypoxaemia, inadequate calorie, or macronutrient intake, $1,13,25-28$ increased energy expenditure relative to intake, ${ }^{29-31}$ increased inflammation, ${ }^{32}$ or associated comorbidities that include gut dysfunction, ${ }^{25}$, respiratory infections, associated genetic syndromes, and reduced growth potential. $^{7,33-37}$

A study of anthropometric data in children with CHD in India showed that recorded dietary intake was not associated with the probability of being underweight. ${ }^{6}$ Another study concluded that there was no reduction in intake in children with CHD relative to normal children, whereas "normal serum prealbumin and albumin in the infants with CHD ruled out protein-calorie malnutrition." ${ }^{36}$ The plasma amino acid profile was normal preoperatively in a group of children with $C H D$, regardless of anthropometric values. ${ }^{38}$ A study from Latin America of children with CHD showed that anthropometric measures of malnutrition were present in $>80 \%$ of the children; albumin and prealbumin levels were lower than in normal controls, although transferrin levels were no different; and that failure to thrive was worse in children with pulmonary hypertension. ${ }^{39}$

In low- and middle-income countries with resource limitations, the prevalence of abnormal preoperative anthropometry is high owing to late presentation, delays in corrective intervention, and 
frequent hospitalisations related to respiratory infections. ${ }^{6,16}$ In a cohort of 100 consecutive infants undergoing ventricular septal defect closure, severe underweight (weight $\mathrm{z}$-score $<-3$ ) was observed in $46 \%$ of patients. ${ }^{33}$ In a prospective study of 476 consecutive patients undergoing corrective intervention for CHD, Vaidyanathan et al reported z-scores $<-2$ in 59\% (weight), 26.3\% (height), and $55.9 \%$ (weight/height), respectively; z-scores $<-3$ were observed in $27.7 \%$ (weight), $10.1 \%$ (height), and $24.2 \%$ (weight/height). ${ }^{6}$ Congestive heart failure, older age at correction, and limited growth potential as suggested by lower birth weight for gestation, lower parental anthropometry, and genetic syndromes were identified as predictors of "malnutrition". The International Quality Improvement Collaborative for Congenital Heart Surgery in lowand middle-income countries uses a registry to collect data from over 50 sites. An analysis of data from 15,049 patients with CHD revealed that $>50 \%$ of children had weight z-scores of -3 or less and $12 \%$ had an emaciated appearance before their surgery. ${ }^{16}$

Although anthropometric measurements in children with CHD are frequently abnormal, classical features of malnutrition such as skin changes, presence of oedema, hair changes, and so on are relatively rare in children with CHD. In the setting of malnutrition in Africa, a discrepancy between clinical signs of acute malnutrition and anthropometry ${ }^{20}$ may be an important issue to pursue.

Finally, there is evidence that micronutrient deficiencies may be relatively common in children with CHD. ${ }^{40}$ This has never been explored in low- and middle-income countries where it is even more likely to be an issue.

Supplementary Table 1 summarises data from publications on nutritional status in CHD from lowand middle-income countries.

\section{Impact of preoperative state on postoperative outcome}

Because of their lower protein and energy reserves, infants and newborns may be particularly vulnerable to the hypercatabolic state that is expected following heart surgery, ${ }^{41,42}$ although hypercatabolism may not follow all paediatric cardiac operations. ${ }^{43}$ This situation is further worsened by comorbidities such as lack of protein:calorie provision or major infections (Fig 1). When the acute phase of metabolic stress resolves, the anabolic phase begins, resulting in somatic growth, with decreasing concentrations of acute-phase reactants, proteins, and total urinary nitrogen values, and with increasing concentrations of visceral proteins. ${ }^{44}$ The timing of transition to the anabolic phase is influenced by the extent of "surgical stress", associated comorbidities, quality of nutritional support, and a number of other potential factors.

Within that framework, there has been concern that cardiac surgery in underweight children with CHD would be associated with worse outcomes. However, there is very little evidence to support the notion that lower weights are associated with poorer surgical outcomes. In a study published in 1992, Hardin et $\mathrm{al}^{45}$ compared two groups of patients undergoing closure of ventricular septal defects $(>4 \mathrm{~kg}$ and $<4 \mathrm{~kg}$ ) and found no significant difference in outcomes.

In a study from southern India on 100 consecutive infants undergoing surgical closure of ventricular septal defects, $46 \%$ had weight z-scores of -3 or lower, although this did not affect postoperative mortality or morbidity, duration of mechanical ventilation, or length-of-stay in the ICU or hospital. ${ }^{16} \mathrm{~A}$ more recent prospective study of 1028 infants from the same centre studied the impact of preoperative factors on postoperative outcomes after congenital heart surgery. ${ }^{17}$ Weight z-scores $<-3$ and low birth weight $(<2.5 \mathrm{~kg})$ did not adversely affect mortality or morbidity. These results reinforce the strategy of early correction of $\mathrm{CHDs}$ irrespective of nutritional status. Preoperative optimisation of nutritional status through aggressive feeding is not necessary in most patients, although it may make sense to use this technique if there are ongoing delays in access to surgical repair.

\section{Correction verses palliation}

The question of correction versus palliation in a severely undernourished child with CHD is likely to be dictated by several factors that include the specific defect, the experience and expertise of the surgical and intensive care teams, and associated comorbidities. Relatively simple CHD that can be corrected through a single operation, such as a ventricular septal defect, should be closed surgically. A study in South Africa demonstrated that when the realities of a staged approach using pulmonary artery banding including loss to follow-up, delays in definitive procedures, the challenges of two surgical procedures in a context with limited surgical time, and so on - were taken into account, mortality after a staged approach using pulmonary artery banding was higher than primary surgical closure of the ventricular septal defect. ${ }^{46}$ Nonetheless, there are clearly situations where pulmonary artery banding may be a useful stage en route to full correction.

\section{Management of undernutrition}

Cardiac teams in low- and middle-income countries are frequently faced with children with CHD who are 
underweight, thin, and stunted. The first response should be to regard that as further evidence that the diagnosis of CHD is being delayed and to focus on interventions to improve early diagnosis and referral.

\section{Preoperative assessment of nutritional status:}

A full preoperative assessment should be obtained as it provides essential baseline information for further monitoring of progress following surgical correction. This would typically include accurate measurements of height, weight, and head circumference. The measurement of biceps or triceps skinfold thickness is a simple method for determining fat stores, which is not routinely performed during preoperative assessment, ${ }^{19}$ but might provide useful data for follow-up, both for individual patients and for patient groups. Laboratory tests that include plasma levels of albumin, transferrin, prealbumin, and retinol-binding protein are seldom undertaken because they are thought to be of limited value.

\section{Nutritional support}

Significant caloric supplementation in children with CHD could lead to improved growth ${ }^{47}$ and, in some, improved growth could be achieved using continuous enteral feeds. ${ }^{48-50}$

Enteral nutrition is the preferred mode of nutritional support in paediatric ICUs. ${ }^{51}$ Enteral nutrition is physiological, has a favourable effect on the intestinal mucosa, and has fewer complications compared with parenteral nutrition. ${ }^{52,53}$ It has the additional benefit that it is considerably cheaper than parenteral nutrition and more easily available in lowand middle-income countries. Intragastric feeding is the most common route, and there are insufficient data to recommend routine use of post-pyloric feeding, unless there are particular concerns such as poor tolerance of gastric feeding or evidence of gastrooesophageal reflux with aspiration. In a single randomised controlled trial in 74 critically ill children, a higher number of patients with post-pyloric feeding reached caloric goals. ${ }^{54}$

There are particular challenges with feeding of neonates before surgery, although in most cases it is possible to start enteral feeding - even while on prostaglandins. Many of these infants may continue to require gavage feeding postoperatively. 55

\section{Postoperative nutrition}

Postoperative enteral feeds should be initiated as soon as possible, and parenteral nutrition should only be used if absolutely essential. Recent data suggest that early parenteral nutrition, within 7 days of admission, in the paediatric ICU is associated with worse patient outcomes, at least in high-income countries. $^{56}$

\section{Initiation and advancement of feeds:}

Guidelines for withholding feeds after paediatric cardiac surgery are not clearly defined, and there are extremely limited data available specific to low- and middle-income countries. The most common concern in early initiation of feeds is the potential for low cardiac output with gut hypoperfusion, especially in neonates with duct-dependent circulation, leading to necrotising enterocolitis. ${ }^{57,58} \mathrm{~W}$ ith careful monitoring and slow advancement of feeds, early enteral nutrition is feasible in most neonates within the first 24 hours. In a retrospective review of 67 neonates, including 52 patients with duct-dependent circulation undergoing surgical repair, postoperative enteral feeds could be initiated within 3 days in $98.5 \%$ $(\mathrm{n}=66) ; 64$ patients could reach full feeds at a median duration of 7.5 days following surgical correction. ${ }^{55}$

In neonates and young infants, feeds are typically started - within 12-24 hours of surgery - at $1 \mathrm{ml} / \mathrm{kg} /$ hour and advanced at the same rate every $4-6$ hours to reach the goal volume. Although continuous feeds have not been shown to minimise aspiration or feed intolerance, it is sometimes resorted to in infants with poor weight gain and feeding complications. ${ }^{49}$ Feeds are withheld before extubation, around invasive procedures, in patients with haemodynamic instability, or with impending respiratory failure.

In the early postoperative phase, feed volume is dictated by the maintenance fluid rate. Fluid intake is usually restricted to $50-80 \%$ of maintenance rate in neonates and infants undergoing open-heart surgery. ${ }^{59}$ On the basis of studies in patients with $\mathrm{CHD}$, the resting energy expenditure is estimated to be $55-75 \mathrm{kcal} / \mathrm{kg} / \mathrm{day}$ in the first $3-5$ days. ${ }^{60}$ This guides initial feeding, which can be escalated to $120-150 \mathrm{kcal} / \mathrm{kg} /$ day with transitioning to step down care to facilitate catch-up growth in infants.

Protein intake is crucial as protein catabolism could manifest as loss of respiratory muscle mass, failed weaning, poor weight gain, depressed immune function, and poor wound healing. In a small study from Brazil, patients became anabolic post-cardiac surgery with a calorie intake of $54 \mathrm{kcal} / \mathrm{kg} /$ day and a protein intake of $1.1 \mathrm{~g} / \mathrm{kg} /$ day. ${ }^{42}$ The decline in C-reactive protein levels to values $<2$ is considered an indirect marker of the onset of the anabolic phase in critically ill patients; however, its relevance in post-cardiac surgical patients has not been proven. ${ }^{59}$

For neonates and infants, particularly in low- and middle-income countries, human breast milk is the preferred form of enteral feeding, although the 
practicalities of maintaining breast milk production in this context may be challenging. ${ }^{61}$ Breast milk is cost-effective, has immunological benefits, promotes better absorption of trace elements, and may even lower the risk of developing necrotising enterocolitis when used exclusively. ${ }^{62}$ In the setting where tight fluid restriction is required, it may be necessary to increase the energy density of feeds - both for formula and expressed breast milk. An energy density of $\sim 1 \mathrm{kcal} / \mathrm{ml}$ is well tolerated. Further increases should be monitored carefully as high calorie density may precipitate osmotic diarrhoea. Cost-effective options to fortify formula feeds include additives such as coconut oil or medium-chain triglyceride oil.

A feeding gastrostomy or jejunostomy may be a reasonable option when long-term enteral nutrition is required in children. ${ }^{63,64}$ It may also be considered in patients with gastro-oesophageal reflux, aspiration, or severe failure to thrive. In a retrospective cohort of 54 patients who required gastrostomy tube placement after surgery for single-ventricle palliation, patients who underwent earlier placement of a gastrostomy tube had shorter ICU and hospital stays. ${ }^{64}$

Monitoring enteral nutrition should include regular audits of weight, fluid and dietary intake, calories prescribed and calories achieved, gastrointestinal function, feeding tube integrity, and feeding complications. Undue attention to gastric residual volumes may be a deterrent to enteral feeding in critical care settings. Decisions to interrupt feeds should be considered with signs of feeding intolerance such as distention, vomiting, or diarrhoea, rather than relying on residual volumes alone. ${ }^{65}$ The most important aspect of monitoring enteral nutrition may be to detect and minimise interruptions in feeding. In a recent prospective study in a paediatric ICU, implementation of a stepwise enteral nutrition algorithm led to a significant decrease in the number of avoidable episodes of feeding interruptions ( $n=3$ versus $n=51$, $p=0.0001)$, shortened the time to reach energy goals from 4 days to 1 ( $p<0.0001)$, and resulted in a higher proportion of patients reaching their energy goals (99 versus $61 \%, \mathrm{p}=0.01$ ). ${ }^{66}$

Underfeeding is common in critically ill children even in most advanced units. ${ }^{67-69}$ Algorithm-led nutritional therapy and attention to energy and protein goals by dedicated nutrition support teams has translated to better postoperative outcomes in highincome countries. ${ }^{68,69}$ However, in emerging economies there is a perceived lack of dedicated nutrition support teams. A viable option is to use existing personnel in monitoring and supervising nutrition delivery. The initial phase should focus on education of in-house staff to bridge knowledge gaps in feeding practices. $^{70}$ As primary caregivers, intensive care nurses should be empowered to initiate, monitor, and maintain nutrition delivery in the postoperative phase. A nutrition algorithm can be formulated to serve as a clinical aid to guide the therapy (Fig 2). This can be successfully integrated into multidisciplinary ICU rounds as nurse-led nutrition rounds. ${ }^{71}$

There are very limited data on recommendations for feeding children who were previously underweight and failing to thrive. We recommend that such children be started on the nutritional programme as outlined above, together with close monitoring of progress and weight gain. Failure to gain weight should stimulate renewed focus on adequacy of the cardiac repair; the presence of complications such as chylothorax, with associated nutritional deficits; and the possibility of other underlying conditions that may cause malabsorption of enteral feeds. In addition, there needs to be focus on optimisation of the diet available to the child, and provision of supplements of essential macronutrients and micronutrients.

\section{Parenteral nutrition}

The overall use of parenteral nutrition in critical care settings in low- and middle-income countries is reported to be very low, ${ }^{72}$ primarily owing to prohibitive costs and lack of dedicated personnel to ensure safe prescription and delivery. In addition, there are the biological complications related to parenteral nutrition including infection, venous thrombosis, electrolyte imbalances, and parenteral nutritioninduced cholestasis. ${ }^{73}$ Notwithstanding these concerns, the use of parenteral nutrition may be warranted in critically ill patients after congenital heart surgery in situations in which enteral feeding is contraindicated or is insufficient to promote adequate growth. Guidelines are available for prescription of parenteral nutrition in children. ${ }^{74}$ Prescription of parenteral nutrition is a complex process with potential for errors, requiring appropriate precautions and systems when used. ${ }^{75}$

\section{Parenteral nutrition in the low-resource environment:}

In paediatric ICUs of low- and middle-income countries, parenteral nutrition should be prescribed only if absolutely indicated. The paediatric intensivist in conjunction with the nurse leader and the hospital clinical pharmacist should be in charge of prescribing and ensuring its safe administration. The feasibility of re-introducing enteral nutrition should be constantly explored. Trophic feeds should be encouraged wherever feasible to prevent intestinal mucosal atrophy. ${ }^{73}$ 


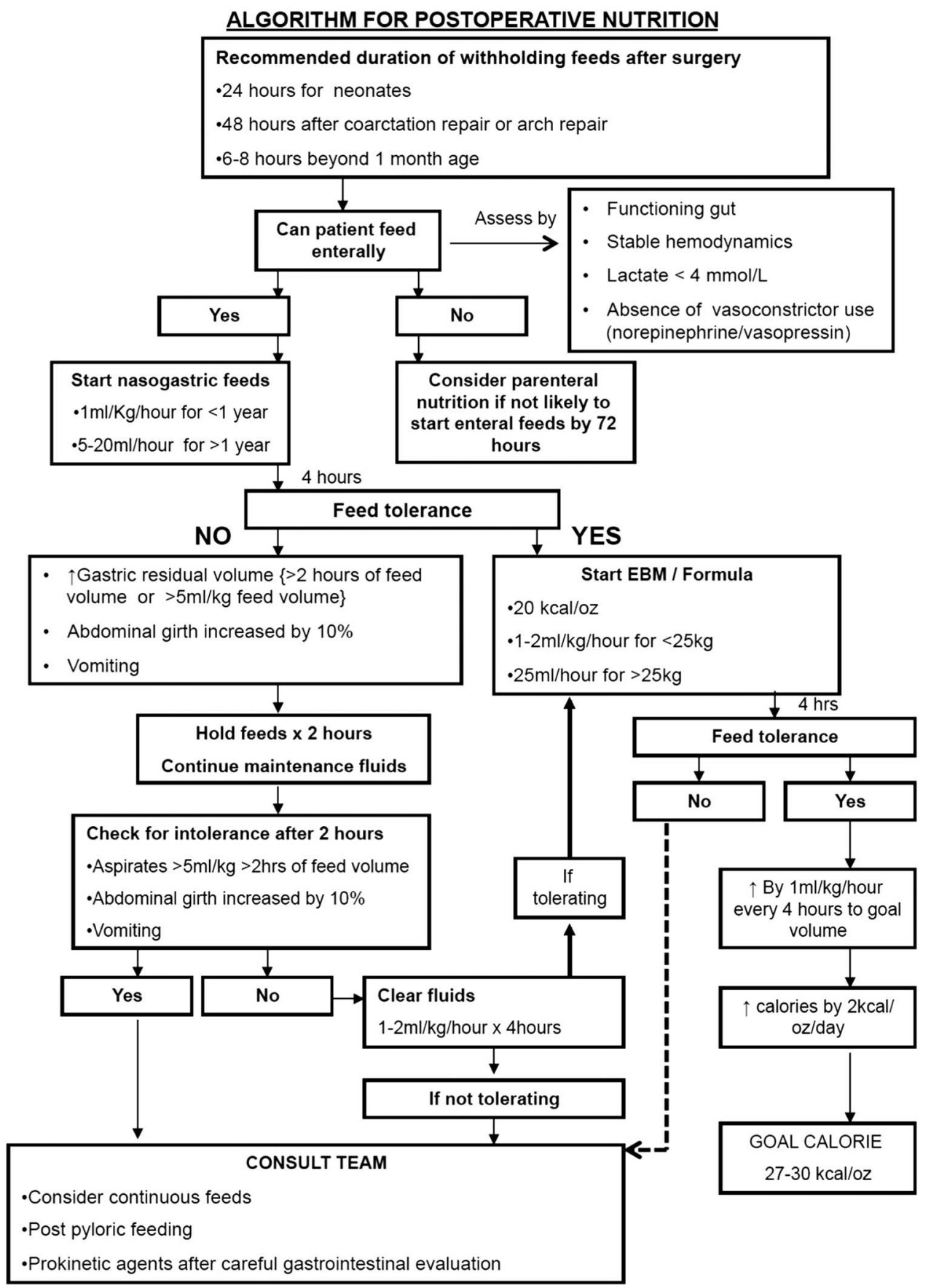

Figure 2 .

Nutritional management in the early postoperative period: suggested algorithm for low-resource environments. EBM $=$ expressed breast milk.

\section{Nutritional recovery after corrective surgery}

Studies from advanced nations have previously reported normalisation of somatic growth typically 6-12 months after corrective congenital heart surgery. ${ }^{34,76}$ Weintraub et $\mathrm{al}^{34}$ reported that after surgical closure of ventricular septal defects in infancy, growth parameters were almost comparable to the reference population by 5.7 years; however, in a study from southern India, the nutritional recovery on follow-up after ventricular septal defect closure in infancy was sub-optimal, with weight and height z-scores $<-2$ in 42 and $27 \%$ of patients, respectively. ${ }^{77}$ In a larger study including all forms of $\mathrm{CHD}$, the same authors reported significant catch-up growth after correction, typically within 3-12 months postoperatively, followed by plateauing of growth curves after 1 year. ${ }^{78}$ This reflects an 
immediate catch-up growth in the short term owing to correction of the haemodynamic derangement. Other determinants of growth such as dietary and constitutional factors play a more important longterm role. Sub-optimal nutritional recovery with persistent weight, z-score $<-2$ was observed in $27 \%$ of patients and this was predicted by lower weight z-score at surgery, lower birth weight, and lower parental anthropometry. ${ }^{78}$ It is important to identify patients at risk of sub-optimal recovery - those with lower growth potential - before intervention so that targeted nutritional rehabilitation may be provided on follow-up.

\section{Review post-surgery and surgical recovery}

Following paediatric ICU discharge, close attention to nutrition is required, particularly in some subsets of patients ${ }^{79}$ such as those with Fontan circulations following complex CHD. ${ }^{80}$ However, this may pose challenges in resource-limited settings.

\section{Future directions}

Ideally, nutritional support for children with CHD should be based on data that are appropriate to specific environments. Although there is a reasonable body of published evidence on the existence of failure of growth and weight gain in children with CHD in low- and middle-income countries (see Supplementary Table 1), there are very limited data available on the optimum way to address these deficits.

Much of the current data on children with CHD are limited to a relatively small spectrum of cardiac anomalies. As increasingly complex CHD is addressed in low- and middle-income countries, the issues related to nutrition may well change and require different approaches. The maintenance of regional databases of information and outcomes would provide an ideal basis for future research in this area.

Much work needs to be done in the areas of quality control and research implementation in order to carry through what is already known into clinical practice. There may need to be increased focus on supporting teams and structures that are implemented for clinicians who work with patients with CHD in low- and middle-income countries.

\section{Conclusions}

The overall management of children with CHD may be complex, and attention to nutrition is a critical element of that care. In general, nutritional support is relatively inexpensive. However, it relies on the existence of a structured system within the cardiac care environment to ensure appropriate recognition of the particular role of nutrition in a specific child. Repeated and accurate measurement of growth parameters together with detailed attention to nutritional intake and tolerance are crucial. It makes little sense to invest in the expense of cardiac surgery while ignoring the associated nutritional challenges.

\section{Acknowledgement}

None.

\section{Financial Support}

This research received no specific grant from any funding agency, commercial, or not-for-profit sectors.

\section{Conflicts of Interest}

None.

\section{Supplementary material}

To view supplementary material for this article, please visit https://doi.org/10.1017/S1047951117 00258X

\section{References}

1. Unger R, DeKleermaeker M, Gidding SS, Christoffel KK. Calories count. Improved weight gain with dietary intervention in congenital heart disease. Am J Dis Child 1992; 146: 1078-1084.

2. Arodiwe I, Chinawa J, Ujunwa F, Adiele D, Ukoha M, Obidike E. Nutritional status of congenital heart disease (CHD) patients: burden and determinant of malnutrition at university of Nigeria teaching hospital Ituku - Ozalla, Enugu. Pak J Med Sci 2015; 31: $1140-1145$.

3. Cameron JW, Rosenthal A, Olson AD. Malnutrition in hospitalized children with congenital heart disease. Arch Pediatr Adolesc Med 1995; 149: 1098-1102.

4. Okoromah CA, Ekure EN, Lesi FE, Okunowo WO, Tijani BO, Okeiyi JC. Prevalence, profile and predictors of malnutrition in children with congenital heart defects: a case-control observational study. Arch Dis Child 2011; 96: 354-360.

5. Toole BJ, Toole LE, Kyle UG, Cabrera AG, Orellana RA, Coss-Bu JA. Perioperative nutritional support and malnutrition in infants and children with congenital heart disease. Congenit Heart Dis 2014; 9: 15-25.

6. Vaidyanathan B, Nair SB, Sundaram KR, et al. Malnutrition in children with congenital heart disease (CHD) determinants and short term impact of corrective intervention. Indian Pediatr 2008; 45: 541-546.

7. Varan B, Tokel K, Yilmaz G. Malnutrition and growth failure in cyanotic and acyanotic congenital heart disease with and without pulmonary hypertension. Arch Dis Child 1999; 81: 49-52.

8. Venugopalan P, Akinbami FO, Al-Hinai KM, Agarwal AK. Malnutrition in children with congenital heart defects. Saudi Med J 2001; 22: 964-967.

9. Villasis-Keever MA, Aquiles Pineda-Cruz R, Halley-Castillo E, Alva-Espinosa C. Frequency and risk factors associated with malnutrition in children with congenital cardiopathy. Salud Publica Mex 2001; 43: 313-323. 
10. Leite HP, Fisberg M, Novo NF, Nogueira EB, Ueda IK. Nutritional assessment and surgical risk markers in children submitted to cardiac surgery. Sao Paulo Med J 1995; 113: 706-714.

11. Ehlers KH. Growth failure in association with congenital heart disease. Pediatr Ann 1978; 7: 750-759.

12. Anderson JB, Beekman RH 3rd, Border WL, et al. Lower weightfor-age $\mathrm{z}$ score adversely affects hospital length of stay after the bidirectional Glenn procedure in 100 infants with a single ventricle. J Thorac Cardiovasc Surg 2009; 138: 397-404.e391.

13. Schwalbe-Terilli CR, Hartman DH, Nagle ML, et al. Enteral feeding and caloric intake in neonates after cardiac surgery. Am J Crit Care 2009; 18: 52-57.

14. Tchervenkov CI, Jacobs JP, Bernier PL, et al. The improvement of care for paediatric and congenital cardiac disease across the world: a challenge for the World Society for Pediatric and Congenital Heart Surgery. Cardiol Young 2008; 18 (Suppl 2): 63-69.

15. Jenkins KJ, Castaneda AR, Cherian KM, et al. Reducing mortality and infections after congenital heart surgery in the developing world. Pediatrics 2014; 134: e1422-e1430.

16. Vaidyanathan B, Roth SJ, Rao SG, Gauvreau K, Shivaprakasha K, Kumar RK. Outcome of ventricular septal defect repair in a developing country. J Pediatr 2002; 140: 736-741.

17. Reddy NS, Kappanayil M, Balachandran R, et al. Preoperative determinants of outcomes of infant heart surgery in a limited-resource setting. Semin Thorac Cardiovasc Surg 2015; 27: 331-338.

18. Bernier PL, Stefanescu A, Samoukovic G, Tchervenkov CI. The challenge of congenital heart disease worldwide: epidemiologic and demographic facts. Semin Thorac Cardiovasc Surg Pediatr Card Surg Annu 2010; 13: 26-34.

19. Global Database on Child Growth and Malnutrition [Online]. 2017. Retrieved April 17, 2017 from http://www.who.int/ nutgrowthdb/about/introduction/en/index 5 .html.

20. Van den Broeck J, Meulemans W, Eeckels R. Nutritional assessment: the problem of clinical-anthropometrical mismatch. Eur J Clin Nutr 1994; 48: 60-65.

21. Green Corkins K. Nutrition-focused physical examination in pediatric patients. Nutr Clin Pract 2015; 30: 203-209.

22. Mehta NM, Corkins MR, Lyman B, et al. Defining pediatric malnutrition: a paradigm shift toward etiology-related definitions. JPEN J Parenter Enteral Nutr 2013; 37: 460-481.

23. Becker P, Carney LN, Corkins MR, et al. Consensus statement of the Academy of Nutrition and Dietetics/American Society for Parenteral and Enteral Nutrition: indicators recommended for the identification and documentation of pediatric malnutrition (undernutrition). Nutr Clin Pract 2015; 30: 147-161.

24. Blasquez A, Clouzeau H, Fayon M, et al. Evaluation of nutritional status and support in children with congenital heart disease. Eur J Clin Nutr 2016; 70: 528-531.

25. Yahav J, Avigad S, Frand M, et al. Assessment of intestinal and cardiorespiratory function in children with congenital heart disease on high-caloric formulas. J Pediatr Gastroenterol Nutr 1985; 4: 778-785.

26. Thommessen M, Heiberg A, Kase BF. Feeding problems in children with congenital heart disease: the impact on energy intake and growth outcome. Eur J Clin Nutr 1992; 46: 457-464.

27. Hansen SR, Dorup I. Energy and nutrient intakes in congenital heart disease. Acta Paediatr 1993; 82: 166-172.

28. Nicholson GT, Clabby ML, Kanter KR, Mahle WT. Caloric intake during the perioperative period and growth failure in infants with congenital heart disease. Pediatr Cardiol 2013; 34: 316-321.

29. Menon G, Poskitt EM. Why does congenital heart disease cause failure to thrive? Arch Dis Child 1985; 60: 1134-1139.

30. Barton JS, Hindmarsh PC, Scrimgeour CM, Rennie MJ, Preece MA. Energy expenditure in congenital heart disease. Arch Dis Child 1994; 70: 5-9.
31. Mitchell IM, Davies PS, Day JM, Pollock JC, Jamieson MP. Energy expenditure in children with congenital heart disease, before and after cardiac surgery. J Thorac Cardiovasc Surg 1994; 107: 374-380.

32. Goulart MR, Schuh DS, Moraes DW, Barbiero SM, Pellanda LC. Serum C-reactive protein levels and body mass index in children and adolescents with CHD. Cardiol Young 2017; 27: 1083-1089.

33. Mehrizi A, Drash A. Growth disturbance in congenital heart disease. J Pediatr 1962; 61: 418-429.

34. Weintraub RG, Menahem S. Growth and congenital heart disease. J Paediatr Child Health 1993; 29: 95-98.

35. Ackerman IL, Karn CA, Denne SC, Ensing GJ, Leitch CA. Total but not resting energy expenditure is increased in infants with ventricular septal defects. Pediatrics 1998; 102: 1172-1177.

36. Salzer HR, Haschke F, Wimmer M, Heil M, Schilling R. Growth and nutritional intake of infants with congenital heart disease. Pediatr Cardiol 1989; 10: 17-23.

37. Matthiesen NB, Henriksen TB, Gaynor JW, et al. Congenital heart defects and indices of fetal cerebral growth in a nationwide cohort of 924422 liveborn infants. Circulation 2016; 133: 566-575.

38. Villares JM, Leal LO, Diaz IS, Gonzalez PG. Plasma aminogram in infants operated on complex congenital heart disease. Nutr Hosp 2008; 23: 283-287.

39. Leite HP, de Camargo Carvalho AC, Fisberg M. Nutritional status of children with congenital heart disease and left-to-right shunt. The importance of the presence of pulmonary hypertension. Arq Bras Cardiol 1995; 65: 403-407.

40. Steier M, Lopez R, Cooperman JM. Riboflavin deficiency in infants and children with heart disease. Am Heart J 1976; 92: 139-143.

41. Finnerty CC, Mabvuure NT, Ali A, Kozar RA, Herndon DN. The surgically induced stress response. JPEN J Parenter Enteral Nutr 2013; 37: 21s-29s.

42. Teixeira-Cintra MA, Monteiro JP, Tremeschin M, Trevilato TM, Halperin ML, Carlotti AP. Monitoring of protein catabolism in neonates and young infants post-cardiac surgery. Acta Paediatr 2011; 100: 977-982.

43. Mehta NM, Costello JM, Bechard LJ, et al. Resting energy expenditure after Fontan surgery in children with single-ventricle heart defects. JPEN J Parenter Enteral Nutr 2012; 36: 685-692.

44. Jones MO, Pierro A, Hammond P, Lloyd DA. The effect of major operations on heart rate, respiratory rate, physical activity, temperature and respiratory gas exchange in infants. Eur J Pediatr Surg 1995; 5: 9-12.

45. Hardin JT, Muskett AD, Canter CE, Martin TC, Spray TL. Primary surgical closure of large ventricular septal defects in small infants. Ann Thorac Surg 1992; 53: 397-401.

46. Brooks A, Geldenhuys A, Zuhlke L, Human P, Zilla P. Pulmonary artery banding: still a valuable option in developing countries? Eur J Cardiothorac Surg 2012; 41: 272-276.

47. Jackson M, Poskitt EM. The effects of high-energy feeding on energy balance and growth in infants with congenital heart disease and failure to thrive. Br J Nutr 1991; 65: 131-143.

48. Bougle D, Iselin M, Kahyat A, Duhamel JF. Nutritional treatment of congenital heart disease. Arch Dis Child 1986; 61: 799-801.

49. Vanderhoof JA, Hofschire PJ, Baluff MA, et al. Continuous enteral feedings. An important adjunct to the management of complex congenital heart disease. Am J Dis Child 1982; 136: 825-827.

50. Schwarz SM, Gewitz MH, See CC, et al. Enteral nutrition in infants with congenital heart disease and growth failure. Pediatrics 1990; 86: 368-373.

51. Skillman HE, Mehta NM. Nutrition therapy in the critically ill child. Curr Opinion Crit Care 2012; 18: 192-198.

52. Zamberlan P, Delgado AF, Leone C, Feferbaum R, Okay TS. Nutrition therapy in a pediatric intensive care unit: indications, monitoring, and complications. JPEN J Parenter Enteral Nutr 2011; 35: 523-529. 
53. Mehta NM. Approach to enteral feeding in the PICU. Nutr Clin Pract 2009; 24: 377-387.

54. Meert KL, Daphtary KM, Metheny NA. Gastric vs small-bowel feeding in critically ill children receiving mechanical ventilation: a randomized controlled trial. Chest 2004; 126: 872-878.

55. Natarajan G, Reddy Anne S, Aggarwal S. Enteral feeding of neonates with congenital heart disease. Neonatology 2010; 98: 330-336.

56. Fivez T, Kerklaan D, Mesotten D, et al. Early versus late parenteral nutrition in critically ill children. N Engl J Med 2016; 374: 1111-1122.

57. Jeffries HE, Wells WJ, Starnes VA, Wetzel RC, Moromisato DY. Gastrointestinal morbidity after Norwood palliation for hypoplastic left heart syndrome. Ann Thorac Surg 2006; 81: 982-987.

58. Giannone PJ, Luce WA, Nankervis CA, Hoffman TM, Wold LE. Necrotizing enterocolitis in neonates with congenital heart disease. Life Sci 2008; 82: 341-347.

59. Owens JL, Musa N. Nutrition support after neonatal cardiac surgery. Nutr Clin Pract 2009; 24: 242-249.

60. De Wit B, Meyer R, Desai A, Macrae D, Pathan N. Challenge of predicting resting energy expenditure in children undergoing surgery for congenital heart disease. Pediatr Crit Care Med 2010; 11: 496-501.

61. Torowicz DL, Seelhorst A, Froh EB, Spatz DL. Human milk and breastfeeding outcomes in infants with congenital heart disease. Breastfeed Med 2015; 10: 31-37.

62. Sullivan S, Schanler RJ, Kim JH, et al. An exclusively human milkbased diet is associated with a lower rate of necrotizing enterocolitis than a diet of human milk and bovine milk-based products. J Pediatr 2010; 156: 562-567.e561.

63. Hofner G, Behrens R, Koch A, Singer H, Hofbeck M. Enteral nutritional support by percutaneous endoscopic gastrostomy in children with congenital heart disease. Pediatr Cardiol 2000; 21: 341-346.

64. El-Sayed Ahmed MM, Alfares FA, Hynes CF, et al. Timing of gastrostomy tube feeding in three-stage palliation of singleventricle physiology. Congenit Heart Dis 2016; 11: 34-38.

65. Lee JH, Rogers E, Chor YK, et al. Optimal nutrition therapy in paediatric critical care in the Asia-Pacific and Middle East: a consensus. Asia Pacific J Clin Nutr 2016; 25: 676-696.

66. Hamilton S, McAleer DM, Ariagno K, et al. A stepwise enteral nutrition algorithm for critically ill children helps achieve nutrient delivery goals. Pediatr Crit Care Med 2014; 15: 583-589.

67. Martinez EE, Smallwood CD, Bechard LJ, Graham RJ, Mehta NM. Metabolic assessment and individualized nutrition in children dependent on mechanical ventilation at home. J Pediatr 2015; 166: 350-357.

68. Mehta NM, Bechard LJ, Cahill N, et al. Nutritional practices and their relationship to clinical outcomes in critically ill children - an international multicenter cohort study. Crit Care Med 2012; 40: 2204-2211.
69. Mehta NM, Bechard LJ, Zurakowski D, Duggan CP, Heyland DK. Adequate enteral protein intake is inversely associated with 60-d mortality in critically ill children: a multicenter, prospective, cohort study. Am J Clin Nutr 2015; 102: 199-206.

70. Martinez EE, Bechard LJ, Mehta NM. Nutrition algorithms and bedside nutrient delivery practices in pediatric intensive care units: an international multicenter cohort study. Nutr Clin Pract 2014; 29: 360-367.

71. Balachandran R, Nair SG, Gopalraj SS, Vaidyanathan B, Kumar RK. Dedicated pediatric cardiac intensive care unit in a developing country: Does it improve the outcome? Ann Pediatr Cardiol 2011; 4: 122-126.

72. Ramakrishnan N, Shankar B, Ranganathan L, Daphnee DK, Bharadwaj A, Venkataraman R. Parenteral nutrition support: beyond gut feeling? Quality control study of parenteral nutrition practices in a tertiary care hospital. Indian J Crit Care Med 2016; 20: 36-39.

73. Heine RG, Bines JE. New approaches to parenteral nutrition in infants and children. J Paediatr Child Health 2002; 38: 433-437.

74. Koletzko B, Goulet O, Hunt J, Krohn K, Shamir R. 1. Guidelines on Paediatric Parenteral Nutrition of the European Society of Paediatric Gastroenterology, Hepatology and Nutrition (ESPGHAN) and the European Society for Clinical Nutrition and Metabolism (ESPEN), supported by the European Society of Paediatric Research (ESPR). J Pediatr Gastroenterol Nutr 2005; 41 (Suppl 2): S1-S87.

75. Boullata JI, Gilbert K, Sacks G, et al. A.S.P.E.N. clinical guidelines: parenteral nutrition ordering, order review, compounding, labeling, and dispensing. JPEN J Parenter Enteral Nutr 2014; 38: 334-377.

76. Cheung MM, Davis AM, Wilkinson JL, Weintraub RG. Long term somatic growth after repair of tetralogy of Fallot: evidence for restoration of genetic growth potential. Heart 2003; 89: $1340-1343$.

77. Vaidyanathan B, Roth SJ, Gauvreau K, Shivaprakasha K, Rao SG, Kumar RK. Somatic growth after ventricular septal defect in malnourished infants. J Pediatr 2006; 149: 205-209.

78. Vaidyanathan B, Radhakrishnan R, Sarala DA, Sundaram KR, Kumar RK. What determines nutritional recovery in malnourished children after correction of congenital heart defects? Pediatrics 2009; 124: e294-e299.

79. Medoff-Cooper B, Ravishankar C. Nutrition and growth in congenital heart disease: a challenge in children. Curr Opin Cardiol 2013; 28: 122-129.

80. Glockler M, Severin T, Arnold R, et al. First description of three patients with multifocal lymphangiomatosis and protein-losing enteropathy following palliation of complex congenital heart disease with total cavo-pulmonary connection. Pediatr Cardiol 2008; 29: 771-774. 